\title{
Multi-organ failure due to influenza A viral infection - A Sri Lankan experience
}

\author{
Sanath P Lamabadusuriya ${ }^{1}$ \\ Sri Lanka Journal of Child Health, 2001; 30: 87-93
}

(Key words: multi-organ failure, influenza A, Sri Lanka)

Professor C. C. de Silva was born in 1904 at Bambalapitiya to an affluent family; his father, Dr. W. H. de Silva was the first Ceylonese to qualify as a fellow of the Royal College of Surgeons of Edinburgh in Ophthalmology and offered his services free to the Government of Ceylon and organised the first ENT and Eye Unit in Colombo. Perhaps Professor C. C. de Silva was greatly influenced by the philanthropy displayed by his ancestors by devoting a greater part of his professional life for the welfare of underprivileged children of our beloved country.

Professor C. C. de Silva had his early education at Bishops College, Government Training College and then at St.Thomas' College, Mt.Lavinia.

He entered the Colombo Medical College in 1922 and after spending a few years joined University College London and Kings College Hospital and graduated MRCS LRCP in 1928. He returned to Ceylon and served at the Chilaw Hospital, in 1929, later at the De Soysa Maternity Hospital and at Gampaha Hospital as the DMO.

He left again for the UK in 1929 and acquired the MRCP London and returned to Ceylon in 1931. As Ceylon was in the midst of a world recession he could not find employment in government service and set up a private practice at Dehiwala and later formed a partnership with Dr. A. M. Fernando.

In 1938 he returned to London to study for the MD and a year later he was back in Ceylon. In 1949 he joined the Faculty of Medicine, University of Ceylon as the first professor of paediatrics. His main clinical interests were nutritional disorders, haemoglobinopathies and infective diarrhoeas. However he had many interests outside the hospital setting. He was instrumental in setting up the convalescent home at Thalagolla for nutritional

${ }^{1}$ Senior Professor of Paediatrics, Faculty of Medicine, University of Colombo.

rehabilitation of malnourished children together with Dr. L. O. Abeyratne. He was a pioneer in the field of family planning contributing extensively towards it from about the mid sixties. He also looked after the health of baby gorillas at the Dehiwala zoo!

He retired in 1966 and I belonged to the last batch of medical students who did the professorial paediatric appointment at LRH, with him.

The topic for the C. C. de Silva oration today is "Multiorgan dysfunction due to influenza A viral infection - A Sri Lankan experience", which would have been close to Professor C. C. de Silva's heart if he was alive today, as he was very interested in infectious diseases and its prevention.

\section{Introduction}

Influenza A virus has caused pandemics from time to time during the last century. In each epidemic a different strain of the virus had been isolated in the past. In the 1918 pandemic which killed over 20 million people worldwide the influenza A H1N1 strain was implicated. The influenza A H2N2 virus was responsible for the 1957 pandemic and in 1968 the influenza A H3N2 virus was isolated in Hong Kong. More recently in 1997 during the avian influenza out break in Hong Kong the influenza A $\mathrm{H} 5 \mathrm{~N} 1$ strain was isolated ${ }^{1,2}$.

The major surface glycoprotein of the influenza virus is a haemagglutinin. Phytogenetic studies have revealed that the new glycoproteins had originated from avian viruses and had entered the human population after re-assortment with human virus strains $^{3,4,5}$. To date as many as 15 different haemagglutinins and 9 neuraminidases have been identified in avian species ${ }^{6,7}$ providing an extensive reservoir of influenza viruses that could be transmitted to other species.

In May 1997 an influenza virus was isolated from the tracheal aspirate of a 3 year old boy in Hong Kong, 
who died from influenza pneumonia complicated by, acute respiratory distress syndrome (ARDS), Reye syndrome, multiorgan failure and disseminated intravascular coagulation. Preliminary laboratory tests could not identify the virus but further analysis revealed the virus to be an influenza A H5N1, a subtype previously not detected in human beings ${ }^{2}$. This virus was found to be genetically closely related to the influenza A $\mathrm{H} 5 \mathrm{~N} 1$ virus isolated from outbreaks of avian influenza in chickens in Hong Kong that preceded the human infection.

Almost 1 year later in April-June 1998 Sri Lanka was ravaged by an island-wide epidemic of viral fever. During a period of 12 days over 37,000 patients were treated as out-patients in government hospitals alone and over 5500 cases were admitted for in-patient care (Table 1).

Table I

Island wide statistics of Flu-like illness 28th April '98 to 10th May '98

\begin{tabular}{|l|c|}
\hline OPD cases & 37391 \\
\hline Admission to wards & 5562 \\
\hline Reye like syndrome & 140 \\
\hline Deaths & 14 \\
\hline
\end{tabular}

(Epidemiological Unit, Colombo)

As the epidemic spread, wide publicity was given in the print and electronic media and there was much apprehension among the public regarding the cause of the epidemic. During this same 12-day period, over 500 patients were admitted for inpatient care at Lady Ridgeway Hospital (LRH) for children, accounting for $45 \%$ of total admissions; there were
18 deaths, contributing to $62 \%$ of total deaths during this period (Table 2).

Table 2

Lady Ridgeway Hospital statistics of Flu-like illness (FLI)

28th April '98 to 10th May '98

\begin{tabular}{|l|l|l|}
\hline & FLI & Total \\
\hline OPD Cases & 175 & 8330 \\
\hline Admissions to wards & $510(45 \%)$ & 1139 \\
\hline Deaths & $18(62 \%)$ & 29 \\
\hline
\end{tabular}

As the epidemic progressed it became clear that many patients were having evidence of hepatic dysfunction with or without other multiorgan involvement. At this stage it was decided to study such patients in greater detail.

\section{Patients and methods}

During the epidemic all patients admitted to the Professorial Paediatric Unit at LRH with a febrile illness and evidence of hepatic dysfunction were studied in greater detail. All these patients had abnormal liver function tests with or without hepatomegaly. For this purpose a preformed questionnaire was used for collection of data. Basic data such as name, age, sex, BHT number, date of admission, date of discharge/ death, residence, main symptoms, use of paracetamol and/or aspirin prior to admission were documented. Weight on admission, level of consciousness, vital signs, pupillary size, presence of icterus, hepatomegaly etc. were also documented. Neurological involvement was staged using Lovejoy's classification (Table 3).

Table 3

Neurological features of a simplified Lovejoy staging

$\begin{array}{ccc}\text { Stage } & \begin{array}{c}\text { Level of } \\ \text { Consciousness } \\ \text { Drowsy }\end{array} & \text { Respiration } \\ 1 & \text { Normal } \\ 2 & \text { Agitated delirium } & \text { Rapid } \\ 3 & \text { Light coma } & \text { Rapid } \\ & & \\ 4 & \text { Deepar coma } & \text { Variable } \\ 5 & \text { Deep coma } & \text { Apnoea }\end{array}$

Lovejoy et al 1974

The investigations done were $\mathrm{FBC}$, random blood sugar, SGPT and SGOT, prothrombin time, blood urea, serum electrolytes, serum bilirubin and urine FR. Blood ammonia levels were not estimated due to lack of facilities. The virological studies were
Response to pain Pupillary response

Appropriate

Appropriate

Decorticate

Decerebrate

Flaccid
Recovery

$\begin{array}{cc}\text { Normal } & - \\ \text { Normal } & 100 \% \\ \begin{array}{c}\text { Normal }+/-3^{\text {rd }} \\ \text { nerve palsy }\end{array} & 66 \% \\ \text { Fixed dilated } & 33 \% \\ \text { Fixed dilated } & 00 \%\end{array}$

performed at the Medical Research Institute, Colombo and later at the Department of Virology, University of Hong Kong; these studies included nasopharyngeal aspirates which were tested for adenovirus, respiratory syncytial virus, influenza A 
and B and para influenza viruses. Samples of sera during the acute and convalescent stages were collected for antibody studies against influenza A and $\mathrm{B}$, dengue and hepatitis A and B. The nasopharyngeal aspirates were cultured as well and subjected to direct fluorescent testing; haemagglutination inhibition tests were also carried out. Pathological studies were carried out in all the patients who died. Four patients had autopsies performed and in three patients where consent was refused for a complete autopsy, postmortem needle biopsies were obtained from the liver for pathological studies. The pathological specimens were processed in the Department of Pathology, Faculty of Medicine, Colombo and were stained with haemotoxylin and eosin.

\section{Results}

A total of 30 patients of 16 boys and 14 girls were studied (male to female ratio of 1.1:1) Their ages ranged from 6 months to 10 years and the vast majority $(87 \%)$ were under 6 years of age. The age distribution is shown in Table 4.

Table 4 Age Distribution

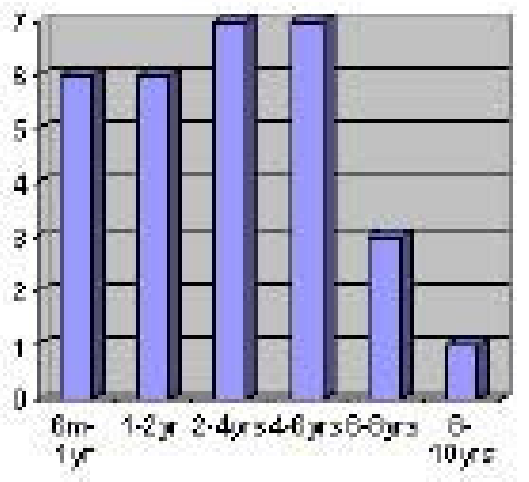

Thirteen patients $(43 \%)$ were from urban areas and $17(57 \%)$ from rural areas. The total duration of illness is summarised in Table 5; 24 patients $(80 \%)$ had an illness between 8-14 days.

Table 5

Duration of illness

\begin{tabular}{|l|c|}
\hline$<7$ days & $03(10 \%)$ \\
\hline $8-14$ days & $24(80 \%)$ \\
\hline $15-21$ days & $03(10 \%)$ \\
\hline
\end{tabular}

The clinical features are summarised in Table 6. As the inclusion criteria included fever, all patients had fever ranging from 2-7 days prior to admission. The other predominant symptoms were drowsiness $(87 \%)$, irritability (77\%), vomiting (53\%) and abdominal pain $(50 \%)$. Two patients had been given aspirin prior to admission. In 7 patients paracetamol in a dose in excess for $100 \mathrm{mg} / \mathrm{kg} / 24 \mathrm{hrs}$. had been administered prior to admission.

Table 6

Clinical features

\begin{tabular}{|l|c|}
\hline Fever & $30(100 \%)$ \\
\hline Drowsiness & $26(87 \%)$ \\
\hline Irritability & $23(77 \%)$ \\
\hline Vomiting & $16(53 \%)$ \\
\hline Abdominal pain & $15(50 \%)$ \\
\hline Seizures & $10(33 \%$ \\
\hline GI bleeding & $09(30 \%)$ \\
\hline Headache & $04(13 \%)$ \\
\hline
\end{tabular}

The majority of patients $(80 \%)$ were undernourished, and had a weight deficit in excess of $25 \%$. The different systems affected are depicted in Table 7. As the inclusion criteria for the study included hepatic dysfunction there was evidence for it in all 30 patients. The other main systems involved were neurological (87\%) and renal in 30\%.

Table 7

Systems affected

\begin{tabular}{|l|c|}
\hline Hepatic & $30(100)$ \\
\hline Neurological & $26(87 \%)$ \\
\hline Renal & $9(30 \%)$ \\
\hline
\end{tabular}

The degree of hepatomegaly is shown in Table 8; in $63 \%$ the lower edge was palpable $2-4 \mathrm{~cm}$ below the right costal margin. Icterus was detected only in 5 patients.

Table 8

Hepatomegaly

(Range N.P - 5cm)

\begin{tabular}{|l|l|}
\hline Not palpable & 03 \\
\hline $1-2 \mathrm{~cm}$ & 07 \\
\hline $2-4 \mathrm{~cm}$ & 19 \\
\hline $5 \mathrm{~cm}$ & 01 \\
\hline
\end{tabular}

The extent of neurological involvement based on the Lovejoy classification is given in Table 9; as can be seen 26 patients had some evidence of it.

Table 9

Neurological involvement (Lovejoy classification)

\begin{tabular}{|l|c|}
\hline No involvement & 04 \\
\hline Stage1 & 11 \\
\hline Stage2 & 6 \\
\hline Stage3 & 8 \\
\hline Stage4 & 1 \\
\hline
\end{tabular}


The WBC/DC showed evidence of neutrophil leucocytosis in 15 patients and leucopenia with lymphopenia in 5 patients. The random blood sugar was below $3.3 \mathrm{mmol} / \mathrm{L}(60 \mathrm{mg} / 100 \mathrm{ml})$ in 13 patients. The prothrombin time was prolonged in $67 \%$ of patients (Table 10).

Table 10

Prothrombin time

\begin{tabular}{|l|c|}
\hline Normal & $10(33 \%)$ \\
\hline$<3$ fold increase & $05(17 \%)$ \\
\hline$>3$ fold increase & $15(50 \%)$ \\
\hline
\end{tabular}

The detailed results of SGPT and SGOT are given in Table 11; as can be seen there was greater than a 3 fold increase, in all except for one patient where the increase was only mild. This increase in the liver enzymes was considered to be very significant as the majority were not jaundiced and therefore resembled Reye syndrome. In the 9 patients with renal involvement, there was elevation of the blood urea levels with appearance of urinary deposits (red cells together with proteinuria) in 9 patients.

Table 11

SGPT results

\begin{tabular}{|c|c|}
\hline$<2$ fold increase & $01(03 \%)$ \\
\hline $2-3$ fold increase & 00 \\
\hline $3-4$ fold increase & $04(14 \%)$ \\
\hline$>4$ fold increase & $25(83 \%)$ \\
\hline
\end{tabular}

Respiratory viruses tested for in nasopharyngeal aspirates are shown in Table 12.

Table 12

Respiratory viruses tested for in nasopharyngeal aspirates

- Adenovirus

- $\quad$ Respiratory syncytial virus (RSV)

- Influenza A \& B

- Parainfluenza

Samples of sera were air-freighted to the Department of Virology, University of Hong Kong for further studies. The virological results are shown in Tables 13 and 14. The causative agent was identified as influenza A H3N2 which was later confirmed in a WHO accredited laboratory in Australia. In 6 patients there was a significant increase in the antibody titre between the acute and convalescent samples. In another 13 patients the antibody titre in the acute sample was significantly elevated. There was no evidence of hepatitis $\mathrm{A}$ or $\mathrm{B}$ infection in a single patient.
Table 13

Positive virological results Influenza A H3N2

\begin{tabular}{|l|c|}
\hline NPA - Direct fluorescence test & 2 \\
\hline NPA - Culture & 1 \\
\hline HI test & 19 \\
\hline
\end{tabular}

Table 14

Virological results (HI test) influenza A H3N2

\begin{tabular}{|l|l|l|}
\hline $\begin{array}{l}\text { Significant rise in antibody } \\
\text { titre (between acute and } \\
\text { convalescent sample) }\end{array}$ & 6 & $22 \%$ \\
\hline Elevated titre in acute sample & 13 & $48 \%$ \\
\hline Negative & 6 & $22 \%$ \\
\hline Inconclusive results & 2 & $8 \%$ \\
\hline $\begin{array}{l}\text { Total Number of patients } \\
\text { (Univ. of Hong Kong) }\end{array}$ & 27 & \\
\hline
\end{tabular}

A summary of the pathological findings are shown in Table 15.

Table 15

Summary of pathological findings

Liver

Microvesicular steatosis

Massive liver cell necrosis

Kidneys $\quad$ Focal tubular necrosis

Lungs Bronchopneumonia

Brain Non-specific changes

In the four patients who had autopsies, the liver was enlarged and yellow in colour. All 7 patients had evidence of liver damage, the predominant findings being microvesicular steatosis together with massive liver cell necrosis. The latter observation was considered to be extremely significant because in classical Reye Syndrome there is no liver cell necrosis and the architecture of the liver is preserved intact.

Macroscopically the kidneys were found to be enlarged and the cortico-medullary junction was indistinct. The pathological changes seen in the kidneys included swelling and vacuolation of the lining cells of the proximal tubule with red cell casts inside the lumen. The glomeruli appeared to be normal. In one patient there was focal tubular necrosis. In the lungs there was evidence of bronchopneumonia with inflammatory exudate in the bronchi. There were also pulmonary interstitial haemorrhages with extension into alveoli. The bronchial epithelial lining was damaged with spill 
over of inflammatory cells into the surrounding interstitial tissue. Macroscopically the brains were swollen with partial obliteration of the sulci. Microscopically cerebral oedema was evident. In one patient (Thirusha) whose case history will be discussed in greater detail, there was a large globular vegetation on one mitral cusp with smaller vegetations on other valve cusps. Microscopically these were found to be due to fungal endocarditis.

Some interesting case reports will now be presented in greater detail.

\section{Case history 1}

A 7 year old girl from Negombo presented with fever for 7 days, progressive drowsiness for 4 days and vomiting for 2 days. On admission her temperature was $40^{\circ} \mathrm{C}$, drowsy, there was no evidence of meningismus but had brisk reflexes with clonus. The liver was not enlarged. She was treated as for an encephalitis/encephalopathy with rapid intravenous infusions of $20 \%$ mannitol. She became deeply unconscious 24 hours later and remained so for 48 hours; on the third day the level of consciousness improved but was noticed to be icteric for the first time. There was no hepatomegaly. The significant laboratory investigations were serum bilirubin 134.5 $\mu \mathrm{mol} / 1$, direct 86.4 and indirect $48.1 \mu \mathrm{mol} / 1$., SGPT 126 U/L (normal 4-20) ,SGOT 91 U/L (normal 0-20), prothrombin time 36 seconds (control 12 seconds), urine-bile positive. Haemagglutination inhibition test for influenza A N3N2 was positive. She was discharged 10 days after admission and on follow-up the liver function tests were normal 1 month later. Virological studies for hepatitis A and B infection were negative.

\section{Case history 2}

A 5 year old boy from Waskaduwa was transferred from General Hospital, Kalutara with a diagnosis of Reye Syndrome. He has had fever and vomiting for 7 days, abdominal pain for 3 days, drowsiness for 2 days and had developed a generalised seizure on the 6th day. The vomitus contained coffee-ground material for 3 days. Prior to admission to Kalutara he had been treated with paracetamol in excess of $150 \mathrm{mg} / \mathrm{kg} /$ day for 5 days. On admission to LRH, he was drowsy and confused, there was no icterus and the liver was enlarged $4 \mathrm{~cm}$ below the right costal margin. The random blood sugar was $1.09 \mathrm{mmol} / \mathrm{l}$, SGPT $120 \mathrm{U} / \mathrm{L}(4-20), \quad$ SGOT $115 \mathrm{U} / \mathrm{L}(0-20)$, prothrombin time $>60$ secs (control 16 secs) and blood urea $3 \mathrm{mmol} / \mathrm{L}$. HI test for influenza H3 N2 was negative in acute sample. He died 12 hours after admission. At post mortem the brain was found to be oedematous, the liver was enlarged and yellowish in colour; there was liver cell necrosis and microvesicular steatosis microscopically. The kidneys were enlarged and showed focal tubular necrosis: Studies for viral hepatitis A and B infection were negative.

\section{Case history 3}

An 18 month old girl from Moratuwa was admitted with a history of fever and cough for 5 days, drowsiness for 2 days and melaena for 1 day. On admission she was febrile, drowsy, not icteric, had bilateral crepitations and rhonchi in the chest and had an enlarged liver $(5 \mathrm{~cm})$. Both SGPT and SGOT were elevated; the prothrombin time was over 60 seconds (control 12 seconds). Blood urea $20.0 \mathrm{mmol} / \mathrm{L}$, Serum creatinine $3.5 \mathrm{mmol} / \mathrm{L}$, Serum $\mathrm{Na} 116.0$ $\mathrm{mmol} / \mathrm{LK}+2.3 \mathrm{mmmol} / \mathrm{L}$. Influenza A H3N2 was cultured from the nasopharyngeal aspirate. After recovery she was discharged one week later and on follow-up the SGPT and SGOT had returned to normal 4 weeks later.

However, she was readmitted 7 weeks after the first admission with a history of fever of 2 days duration and drowsiness. She was found to be drowsy, not icteric, liver was enlarged $(3 \mathrm{~cm})$, BP $120 / 90 \mathrm{~mm}$ of $\mathrm{Hg}$ and had a systolic murmur. There was profuse vomiting after admission and she developed focal seizures on the right side, 2 days later. The investigations at this stage revealed SGPT 68U/L (420), SGOT $32 \mathrm{U} / \mathrm{L}(0-20)$, urine full report - proteins ++ , pus cells $8-10 / \mathrm{hpf}$, red cells $1-2 / \mathrm{hpf}$, blood urea $25 \mathrm{mmol} / \mathrm{L}$ serum proteins $7.28 \mathrm{~g} / \mathrm{dl}$, albumin 3.7 $\mathrm{g} / \mathrm{dl}$, globulin $3.5 \mathrm{~g} / \mathrm{dl}$. She died suddenly of acute pulmonary oedema. There was no laboratory evidence of viral hepatitis A or B. Influenza A H3N2 virus isolated from the nasopharyngeal aspirate and the HI test for Influenza A H3N2 was positive in the acute sample.

At autopsy, the liver was enlarged, yellowish and showed microvesicular steatosis and massive liver cells necrosis. Kidneys showed infarction. In the heart there were large vegetations on mitral valve cusps and on microscopy there were fungal spores and hyphae compatible with Aspergillus. Lungs showed evidence of pulmonary oedema.

\section{Discussion}

In 1963 Reye et $\mathrm{al}^{8}$ described a new entity in children where the hallmarks of the disease were an acute encephalopathy with liver dysfunction. Since then it 
has been reported worldwide including Sri Lanka ${ }^{9}$. In some cases of Reye syndrome there is fatty degeneration of other viscera also but invariably the cause of death is severe cerebral oedema. Another unique feature of Reye syndrome is the absence of jaundice in the majority of cases coupled with microvesicular steatosis without liver cell necrosis. The acute liver cell dysfunction is attributed to mitochondrial damage. The exact aetiology of Reye syndrome is not known although aspirin ingestion has been associated; infections such as influenza B and varicella have also been associated. Reye-like syndrome is similar to Reye Syndrome but associated with inherited metabolic defects ${ }^{10}$. Because of the close association between aspirin therapy and febrile illnesses in children and the occurrence of Reye syndrome, its use in such children is strongly dissuaded $^{11}$.

In this outbreak there were some features resembling Reye or Reye-like Syndrome. These are summarised in Table 16. In summary these were a preceding febrile illness (? viral), persistent vomiting, evidence of an encephalopathy and hepatomegaly with evidence hepatic dysfunction. However initially even clinically it was apparent that the patients were afflicted with something different.

\section{Table 16}

\section{Similarities with Reye or Reye-like syndrome}

Preceding febrile (?viral) illness

Persistent vomiting

Complications seen predominantly in children

Evidence of CNS dysfunction

Hepatomegaly with evidence of hepatic dysfunction

Few patients developed deep jaundice and some had renal dysfunction. When the pathological investigations became available another striking disparity from Reye syndrome was evidence of liver cell necrosis (in the presence of microvesicular steatosis). Moreover, Reye syndrome occurs sporadically whilst the present outbreak was of epidemic nature. Lastly in Reye syndrome influenza $B$ viral infection has been incriminated whilst in the present outbreak influenza A virus was isolated (See Table 17).

Table 17

Contrasting features from Reye or Reye-like syndrome

Influenza B and not influenza A has been incriminated earlier Evidence of live cell necrosis Evidence of renal dysfunction Presence of deep jaundice in a few patients Epidemic nature

There were many similarities with the avian influenza viral outbreak reported from Hong Kong in $1997^{1,2}$. All 12 patients were children with a median age of 9 years and were of Asian descent. All patients had fever, 8 had symptoms or signs of upper respiratory tract infection and five had clinical and radiological evidence of pneumonia at presentation. Hepatic dysfunction had been noted in 6 of the 10 patients who had liver function tests. Three patients had developed renal failure, pulmonary haemorrhage in one patient, acute respiratory distress syndrome in 6 and septic shock in one patient. Interestingly one patient who developed Reye Syndrome had been treated with aspirin, mefenamic acid, paracetamol and diclofenac sodium for control of persistent fever during the week prior to admission. Antiviral agents such as amantadine had been given to 8 patients one patient had received intravenous ribavarin. However in spite of intensive care management 5 patients had developed multiple organ failure and died. In this outbreak the causative agent was identified as the avian influenza A H5N1 virus (See Table 18). In our study, antiviral agents were not used primarily because of non-availability and cost. Based on the Hong Kong study it may have not influenced the outcome however.
Table 18

\section{Comparison of out breaks}

Hong Kong

All 12 patients, children

All had fever

Hepatic dysfunction in majority

Multi-organ involvement

(liver, kidneys, lungs)

Due to Influenza A H5N1
Sri Lanka

Majority children

Fever, predominant symptom

Hepatic dysfunction in majority

Multi-organ involvement

(liver, kidneys, lungs, brain)

Due to Influenza A H3N2 
In the Sri Lankan epidemic it is not clear how the virus had entered the community. However there was very rapid person to person transmission once the disease was established. The hot dry climate in April and the clustering of members of the public at the time of the Sinhala and Tamil New Year would have enhanced further spread.

This is the first study in Sri Lanka to document the multiple organ involvement associated with influenza A viral infection; although an outbreak was reported from Hong Kong during the previous year, it was due to the influenza A H5N1 strain whilst the Sri Lankan epidemic was attributed to the influenza A H3N2 strain. The influenza virus is notorious for undergoing antigenic shifts and drifts frequently. In this context before advocating the use of a vaccine in such circumstances, the efficacy of the vaccine against the prevalent viral strain should be verified.

In this study, 7 patients $(23 \%)$ had received paracetamol in excess of $100 \mathrm{mg} / \mathrm{kg} / 24 \mathrm{hr}$ prior to admission. As paracetamol is hepatotoxic in excessive doses, it would have contributed to the severity of the illness in those patients. It was also unfortunate to find that 2 patients had been treated with aspirin as well.

The public as well as the medical profession should be educated about the adverse effects of antipyretics in children when used inappropriately. In conclusion, a new strain of virus caused a very sudden epidemic in our population which resulted in death complicated by multiorgan failure. It is recommended that unusual clinical presentations should be studied in greater detail. Facilities for virological studies are grossly inadequate in Sri Lanka and a fast track service to regional laboratories should be established to study such outbreaks.

\section{Acknowledgements}

The following contributed to the study as follows; Prasanna Liyanage, Registrar ward 1 for collection of data and coordination of study, Geethani Wickramasinghe, Virologist, MRI and Malik Peiris, Virologist, University of Hong Kong for virological studies, Chandu de Silva Pathologist, Faculty of Medicine, Colombo for pathological studies, Wimal Jayantha, Director, Lady Ridgeway Hospital for granting permission for the studies, Pujitha Wickramasinghe and R. Ajanthan for the illustrations, the medical illustration unit, Faculty of Medicine, Colombo for photography. Their contributions are gratefully acknowledged. Thanks are also due to Hemamali Pathmathilake for secretarial assistance

\section{References}

1. Yuen K Y, Chan P K S, Peiris M et al. Clinical features and rapid viral diagnosis of human disease associated with avian Influenza A H5N1 virus. Lancet 1998; 351: 467-71.

2. Class E C J, Osterhaus A D M E, van Beek R etal. Human influenza A H5N1 virus related to a highly pathogenic avian influenza virus. Lancet 1998; 351: 472-7.

3. Webster R G, Laver W G. Studies on the origin of pandemic influenza. Antigenic analysis of A2 influenza viruses isolated before and after appearance of Hong Kong influenza using antisera to the isolated hemagglutinin subunits. Virology 1972; 48: 433-44.

4. Scholtissek C, Rohde W, Von Hoyningen V, Rott R. On the origin of the human influenza A virus subtypes H2N2 and H3N2. Virology 1978; 87: 13-20.

5. Kawaoka Y, Krauss S, Webster R G. Avian-tohuman transmission of the PB1 of influenza A viruses in the 1957 and 1968 pandemics. J.Virol 1989; 63: 4603-08.

6. Webster RG, Bean W J, Gorman O T, Chambers T M, Kawaoka Y. Evolution and ecology of influenza A viruses. Microbiol Rev. 1992; 56: 152-79.

7. Rohm C, Zhou N, Suss J, MacKenzie J, Webster R G. Characterization of a novel influenza hemagglutinin, H15: criteria for determination of Influenza A subtypes. Virology 1996; 217: 50816.

8. Reye R D K, Morgan G, Baral J . Encephalopathy and fatty degeneration of the viscera: a disease entity in childhood. Lancet 1963; ii :749-52.

9. de Silva D D S, Chandrasoma P T, Lamabadusuriya S P. Reye's syndrome in Sri Lanka. Ceylon Medical Journal 1975; 20: 219224.

10. Glasgow JFT, Moore R. Current concepts in Reye's syndrome. British Journal of Hospital Medicine 1993; 50: 599-604. 

